\title{
The Effect of Aging on the Cracking Resistance of Recycled Asphalt
}

\author{
Mojtaba Mohammadafzali, ${ }^{1}$ Hesham Ali, ${ }^{1}$ James A. Musselman, \\ Gregory A. Sholar, ${ }^{3}$ and Aidin Massahi ${ }^{1}$ \\ ${ }^{1}$ Department of Civil and Environmental Engineering, Florida International University, Miami, FL, USA \\ ${ }^{2}$ Oldcastle Materials Group, Lutz, FL, USA \\ ${ }^{3}$ State Material Office, Florida Department of Transportation, Gainesville, FL, USA
}

Correspondence should be addressed to Mojtaba Mohammadafzali; mmoha020@fiu.edu

Received 30 January 2017; Accepted 7 June 2017; Published 21 August 2017

Academic Editor: Luigi Di Sarno

Copyright (C) 2017 Mojtaba Mohammadafzali et al. This is an open access article distributed under the Creative Commons Attribution License, which permits unrestricted use, distribution, and reproduction in any medium, provided the original work is properly cited.

\begin{abstract}
Fatigue cracking is an important concern when a high percentage of Reclaimed Asphalt Pavement (RAP) is used in an asphalt mixture. The aging of the asphalt binder reduces its ductility and makes the pavement more susceptible to cracking. Rejuvenators are often added to high-RAP mixtures to enhance their performance. The aging of a rejuvenated binder is different from virgin asphalt. Therefore, the effect of aging on a recycled asphalt mixture can be different from its effect on a new one. This study evaluated the cracking resistance of $100 \%$ recycled asphalt binders and mixtures and investigated the effect of aging on this performance parameter. The cracking resistance of the binder samples was tested by a Bending Beam Rheometer. An accelerated pavement weathering system was used to age the asphalt mixtures and their cracking resistance was evaluated by the Texas Overlay Test. The results from binder and mixture tests mutually indicated that rejuvenated asphalt has a significantly better cracking resistance than virgin asphalt. Rejuvenated mixtures generally aged more rapidly, and the rate of aging was different for different rejuvenators.
\end{abstract}

\section{Introduction}

The use of asphalt pavement recycling methods as alternatives to milling and resurfacing has increased significantly in recent years [1]. When used properly, pavement recycling can result in benefits such as cost savings, decreasing the demand for new material and minimizing emissions due to material transportation [2]. Some asphalt recycling methods, such as Hot In-place Recycling (HIR) and Cold In-place Recycling, require incorporating $100 \%$ or close to $100 \%$ Reclaimed Asphalt Pavement (RAP) material [1].

Ideally, a properly recycled pavement should have a good initial performance, compared to a new pavement, and its performance should not drop faster than that of a new pavement. In-place recycled pavements often use $100 \%$ or close to $100 \%$ RAP material. Therefore, their behavior can be different from new mixtures. Cracking resistance and durability are among important performance parameters.
Rejuvenators and other additives are often used to enhance the properties of the recycled material $[3,4]$. The use of rejuvenators can also prevent segregation problems that are caused by the lack of appropriate adhesion of the binder and improve the bond strength of asphalt overlays $[5,6]$. Some previous studies show that the performance of recycled mixtures is equally good or better than new mixtures. A study that used the Indirect Tensile Strength test and Asphalt Pavement Analyzer showed that mixtures containing RAP successfully passed specification requirements and generally had better performance than new mixtures [7]. A more comprehensive work that included using the energy ratio concept confirmed that inclusion of RAP generally increases the tensile strength. However, it was concluded that since recycled mixtures have lower rates of dissipated creep strain energy and the energy imposed on them is more likely to turn into damage, they may have a shorter fatigue life [8]. According to recent work that used semicircular bending, 
Texas overlay, dynamic modulus, and simplified viscoelastic continuum damage tests, the quality of the RAP has a greater effect on the cracking resistance of the mixture than its quantity [9].

Limited research has investigated the cracking performance of $100 \%$ RAP mixtures. Recent work with $100 \%$ RAP mixtures, which were rejuvenated by nine rejuvenators, showed that all rejuvenated mixtures had higher creep compliance than a reference virgin asphalt mixture, and a majority of them also had higher fracture energy. However, four rejuvenated mixtures failed to achieve an equally good or better tensile strength [10].

One of the most significant approaches toward sustainable development is maximizing the use of recycled material. In the construction industry, a huge amount of waste material, including concrete [11], asphalt, and structural steel, is wasted, because of the concerns about their performance and durability. In order to design durable recycled pavements, especially for in-place recycling methods, it is necessary to know more about the cracking resistance of rejuvenated binders and mixtures and how it changes over time. In particular, there is a knowledge gap about the effect of aging on the long-term cracking resistance of recycled asphalt. The objective of this study was to evaluate the cracking resistance of rejuvenated binders and rejuvenated 100\% RAP mixtures. Also, the effect of aging on this parameter was investigated.

\section{Materials and Methods}

This research used both binder and mixture tests. The cracking resistance of rejuvenated binders was assessed by Bending Beam Rheometer (BBR) testing, and aging of the binder was simulated by a Pressure Aging Vessel (PAV). The cracking resistance of rejuvenated mixtures was evaluated and compared with that of new mixtures using the Texas Overlay Test (TOT). The aging of the mix was simulated by the Accelerated Pavement Weathering System (APWS), and changes in the cracking resistance were studied. The following two sections explain the material and test methods used in binder testing and mixture testing experiments.

2.1. Binder Tests. The cracking resistance of rejuvenated binders was evaluated by the BBR test. The PAV was used to simulate binder aging. Samples were tested after the conventional aging proposed in AASHTO M 320, as well as after an extended aging to monitor changes in their properties over time.

Two types of PG 67-22 virgin asphalt were obtained as control samples. Rejuvenated samples were prepared by mixing artificially aged binder with rejuvenators. Rejuvenators used in this study were commercial rejuvenating agents. However, their commercial names are not revealed in this paper and they are identified with fictitious names. The rejuvenators included a heavy paraffinic distilled solvent extract (HPE) and a water-based emulsion from wax-free naphthenic crude with a residue content of $60 \%$ (CWE). These rejuvenators made the most durable rejuvenated binders in a binder aging study by the authors of the current paper [12].

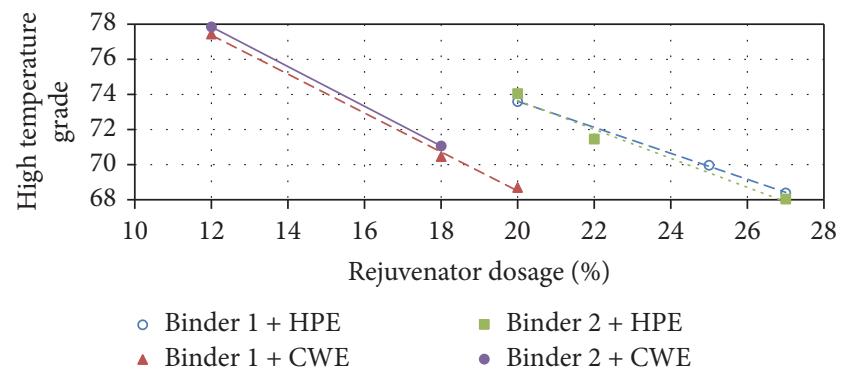

FIGURE 1: Softening curves for binder testing.

PG 95-15 is considered the typical grade for RAP binder based on Florida's experience with binders recovered from RAP [12]. The initial true high temperature grades of the virgin binders were $68.36^{\circ} \mathrm{C}$ for Binder 1 and $71.63^{\circ} \mathrm{C}$ for Binder 2. The binders were aged by the PAV until their high temperature grades reached $95^{\circ} \mathrm{C}$. Afterward, softening curves were established for each binder and each rejuvenator, as presented in Figure 1.

The curves for the CWE samples were established based on the mass of the residue. Aged binders were mixed with appropriate dosages of rejuvenators, and the high temperature grades reduced to the grades similar to those of virgin binders. All virgin and rejuvenated samples underwent two aging procedures:

(1) Standard aging: Rolling Thin Film Oven (RTFO) plus 20 hours PAV, as recommended in AASHTO M320 for BBR test samples.

(2) Extended aging: 60 hours PAV aging.

2.2. Mixture Tests. The TOT was used to measure the cracking resistance of rejuvenated mixtures and compare it to that of the control mixtures. To assess durability, the rejuvenated mixtures underwent accelerated aging by the APWS. Two samples of rejuvenated mixture and two control samples were used in this study.

2.2.1. Sample Preparation. The RAP was sampled from an HIR project in Florida. The asphalt mat was heated to an average temperature of $250^{\circ} \mathrm{F}$ and then milled to a 1-inch depth. The material was collected from the windrow prior to the introduction of the rejuvenator. Thus, this mixture represents the nonrejuvenated RAP. The virgin binder used for the control mixtures was a PG 67-22 nonmodified asphalt. The same rejuvenators used in the binder testing (HPE and CWE) were used for rejuvenating the RAP.

Control Samples. Two control mixtures were used. Control I consisted of the aggregate extracted from the mixture and then blended with virgin asphalt binder. The aggregates were extracted from the mixture using an ignition oven. The asphalt content was determined in accordance with AASHTO $\mathrm{T} 308$ using the provided calibration factor of 0.1 . Then, the extracted aggregate was mixed with a PG 67-22 binder at the same binder content as determined by extraction (6.3\%). 
TABLE 1: Performance grade of the recovered binder.

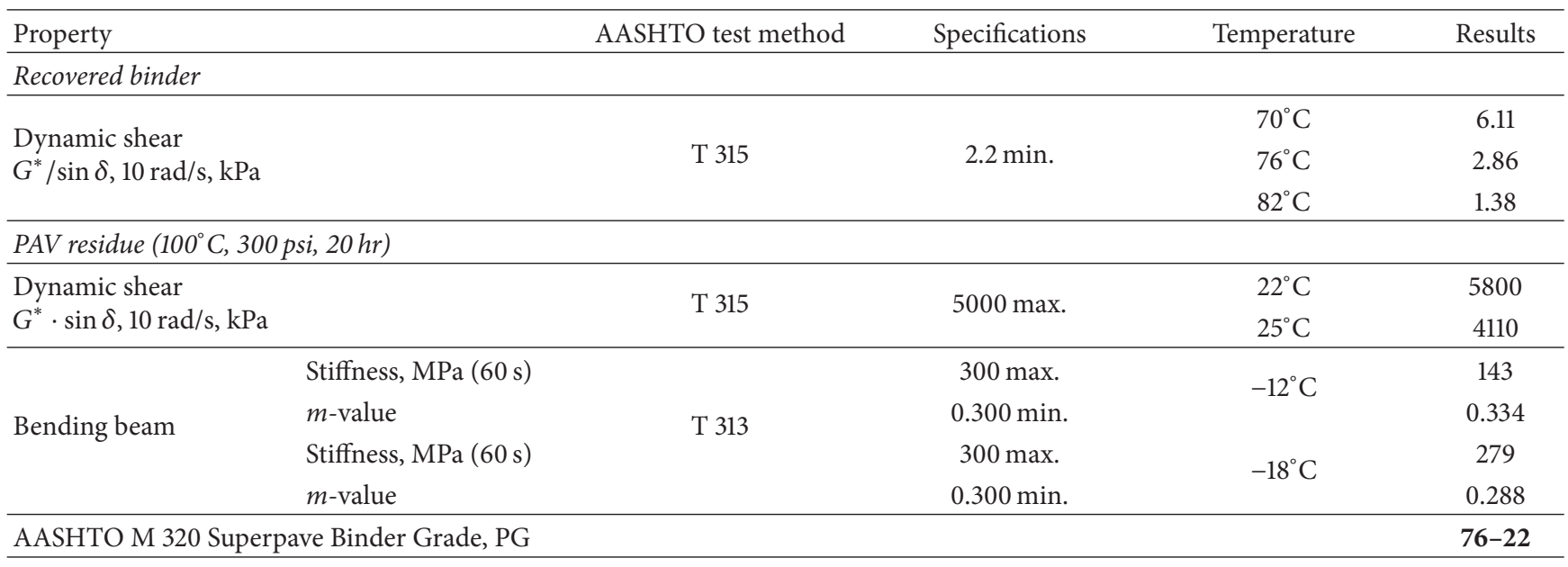

Control II samples were SP-9.5 mixtures, prepared according to FDOT requirements. These samples represented common asphalt mixtures used in Florida with gradations similar to the obtained RAP.

Rejuvenated Samples. The two rejuvenated samples were the RAP mixtures, softened by CWE and HPE rejuvenators. To characterize the binder and establish softening curves, 180 grams of binder was recovered in accordance with ASTM D5404. The PG was determined in accordance with AASHTO M320, as presented in Table 1. The mixture experienced heating when being milled and sampled. This heating was estimated to have almost the same aging effect as construction heating. Therefore, the criterion for the RTFO residue $\left(G^{*} / \sin \delta<2.2 \mathrm{kPa}\right)$ was used to determine its high temperature grade.

A softening curve was established for each rejuvenator when blended with the recovered RAP binder. The purpose of establishing the curves was to determine the dosage needed to reduce the high performance grade temperature to $67^{\circ} \mathrm{C}$. Figure 2 shows the softening curves, and Table 2 displays the rejuvenator percentages of the mixtures and their high temperature PGs. All percentages are reported by the Total Weight of Mixture (TWM).

Rejuvenated samples were prepared by mixing the RAP with appropriate amounts of rejuvenator and 3\% screening sand. The sand was added to the mixture to account for the breakdown in the ignition oven that the Control I aggregate would experience.

The Control I and the rejuvenated mixtures were evaluated for their design at 50 gyrations, and their maximum specific gravity was determined in accordance with ASTM D 2041. Table 3 displays some properties of the specimens.

2.2.2. Testing Procedures. The cracking resistance of samples was tested by the TOT in accordance with the Tex 248-F specifications [13]. First, three replicates of all samples were tested. The Control II was tested only in the initial stage. Three replicate specimens from $\mathrm{CWE}$ and $\mathrm{HPE}$ mixtures, along with

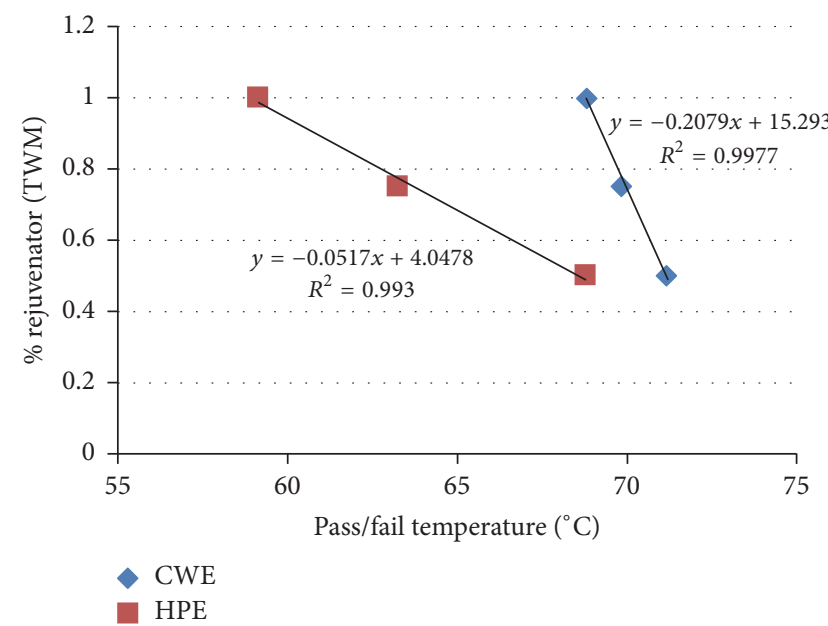

FIGURE 2: Softening curves of rejuvenators mixed with recovered RAP.

two replicates from the Control I, were aged in the APWS for 1,000 hours. Two other replicates from rejuvenated samples were exposed to the APWS for 3,000 hours. A 3,000-hour APWS exposure simulates the aging that occurs in the field in 7 to 10 years [14]. A brief description of TOT and APWS follows.

Texas Overlay Test. The TOT was developed by the Texas Department of Transportation to evaluate the susceptibility of asphalt mixtures to fatigue and reflective cracking. This apparatus applies repeated tension loads to the specimen to simulate the repeated opening and closing of pavement joints and cracks due to temperature variations and traffic loading.

Accelerated Pavement Weathering System (APWS). The longterm aging of pavements is affected by many environmental factors such as temperature, ultraviolet radiation, and water exposure. The Superpave aging protocols, RTFO and PAV, age only the asphalt binder. Also, they are not capable of simulating the effects of all of the affecting factors. The aging 
TABLE 2: Rejuvenator percentage and high temperature grades of samples.

\begin{tabular}{lccc}
\hline Mixture & Binder & Rejuvenator \% (TWM) & High temperature true grade \\
\hline RAP & RAP binder & 0 & $78.2^{\circ} \mathrm{C}$ \\
CWE & Rejuvenated binder & 1 & $68.8^{\circ} \mathrm{C}$ \\
HPE & Rejuvenated binder & 0.5 & $68.8^{\circ} \mathrm{C}$ \\
Control I & Virgin PG 67-22 & 0 & 67.3 \\
Control II & Virgin PG 67-22 & 0 & 67.0 (design value) \\
\hline
\end{tabular}

TABLE 3: Properties of mixtures.

\begin{tabular}{lccccc}
\hline \multirow{2}{*}{ Property } & \multirow{2}{*}{ Test method } & \multicolumn{2}{c}{ Control II } & \multicolumn{2}{c}{ Sample } \\
& & SP-9.5 & FC-9.5 & Control I & CWE \\
\hline Asphalt content, \% & AASHTO T 308 & 6.5 & 7.5 & 6.3 & 6.3 \\
Maximum specific gravity & ASTM D 2041 & 2.362 & 2.359 & 2.375 & 2.361 \\
Air voids\% & ASTM D 3203 & 4.36 & 4.58 & 5.8 & 2.368 \\
\hline
\end{tabular}

of asphalt pavement material varies by the pavement's depth. While surface layers experience more intense aging, less aging occurs in deeper layers [15]. The APWS is designed by PRI Asphalt Technologies, Inc. to apply accelerated aging on asphalt pavement specimens. It ages specimens by simulating rain, sunshine, and temperature variations, which are major factors that cause aging of the surface layers of pavement. Grzybowski et al. explained the development of this system and showed that the aging profile resulting from the APWS aging is similar to that observed in real pavements [16].

\section{Test Results and Discussions}

3.1. Binder Tests. The tests were performed at $-6^{\circ} \mathrm{C}$ and $-12^{\circ} \mathrm{C}$ for samples that had experienced standard aging and at $-6^{\circ} \mathrm{C}$, $-12^{\circ} \mathrm{C}$ and $-18^{\circ} \mathrm{C}$ for those that underwent extended aging. Table 4 presents results from the BBR tests.

Two major parameters are obtained from a BBR test: creep stiffness $(S)$ and stress relaxation parameter ( $m$-value) at $60^{\circ} \mathrm{C}$. The low temperature grade is determined based on these two parameters. In all cases in this study, the $m$ value was more critical, and hence it determined the low temperature grade of all of the samples. There is no agreement in the existing research on whether the $m$-value or the stiffness is the more important parameter to determine the cracking resistance of the pavement. While some studies such as [17] indicate that the low temperature thermal stress development is primarily controlled by the creep stiffness $(S)$, other studies such as $[18,19]$ show that $m$-value is the more significant factor that determines the brittleness of the binder.

Rejuvenated samples generally had significantly lower creep stiffness than virgin binders. This is despite the fact that all samples had similar initial high temperature grades. Also, the $m$-value was higher for rejuvenated samples. It is concluded from these observations that properly rejuvenated binders have better cracking performance than virgin binders.
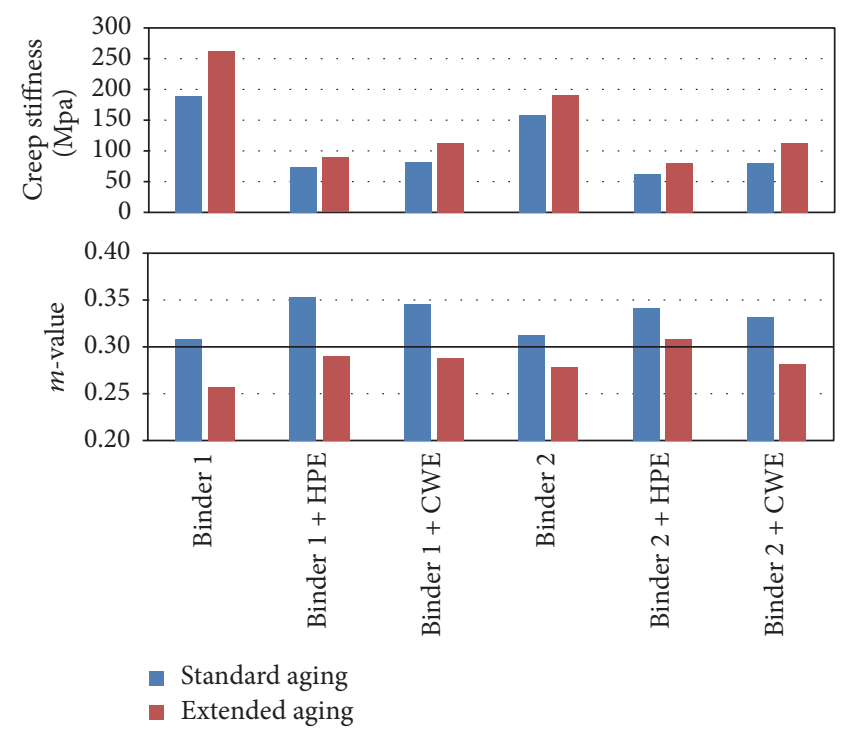

Figure 3: Creep stiffness and $m$-values of binders at $12^{\circ} \mathrm{C}$.

By increasing the aging from the standard to the extended aging, the stiffness of all samples increased, and their $m$-value decreased. Even after 60 hours of PAV aging, the stiffness of rejuvenated binders was lower than the stiffness limit for PG 67-22 ( $\leq 300 \mathrm{MPa}$ at $\left.-12^{\circ} \mathrm{C}\right)$. However, in most cases, the $m$-values were too low and did not meet the requirement $\left(m \geq 0.300\right.$ at $\left.-12^{\circ} \mathrm{C}\right)$. Figure 3 displays the stiffness and $m$-value results of each sample after standard and extended aging.

3.2. Mixture Tests. Table 5 displays the results from the TOT before and after APWS aging. At the initial stage (0 hours), significant differences were observed between the cracking resistance of samples made with rejuvenated binder and those with virgin asphalt. The average number of cycles to failure (ANCF) was considered an indication of susceptibility of mixtures to fatigue and reflective cracking. 
TABLE 4: BBR test results.

\begin{tabular}{|c|c|c|c|c|c|c|c|c|}
\hline Aging & Binder & Rejuvenator & Temp. $\left({ }^{\circ} \mathrm{C}\right)$ & $\begin{array}{l}\text { Creep stiffness } \\
(\mathrm{MPa})\end{array}$ & $m$-value & $\begin{array}{c}\text { Stiffness } \\
\text { critical temp. }\left({ }^{\circ} \mathrm{C}\right)\end{array}$ & $\begin{array}{c}m \text {-value } \\
\text { critical temp. }\left({ }^{\circ} \mathrm{C}\right)\end{array}$ & $\begin{array}{l}\text { High temp. true } \\
\text { grade }\left({ }^{\circ} \mathrm{C}\right)\end{array}$ \\
\hline \multirow{12}{*}{$\begin{array}{l}\text { Standard aging } \\
\text { RTFO + } 20 \text { hours } \\
\text { PAV }\end{array}$} & \multirow{6}{*}{ Binder 1} & \multirow{2}{*}{ Original } & -12 & 190 & 0.309 & \multirow{2}{*}{-25.4} & \multirow{2}{*}{-22.7} & \multirow{2}{*}{87.7} \\
\hline & & & -18 & 430 & 0.228 & & & \\
\hline & & \multirow{2}{*}{ HPE } & -12 & 72.8 & 0.353 & \multirow{2}{*}{-31.5} & \multirow{2}{*}{-25.9} & \multirow{2}{*}{83.4} \\
\hline & & & -18 & 178 & 0.27 & & & \\
\hline & & \multirow{2}{*}{ CWE } & -12 & 81.1 & 0.346 & \multirow{2}{*}{-31.4} & \multirow{2}{*}{-26.8} & \multirow{2}{*}{81.9} \\
\hline & & & -18 & 187 & 0.288 & & & \\
\hline & \multirow{6}{*}{ Binder 2} & \multirow{2}{*}{ Original } & -12 & 159 & 0.313 & \multirow{2}{*}{-27.5} & \multirow{2}{*}{-24.2} & \multirow{2}{*}{91.4} \\
\hline & & & -18 & 319 & 0.277 & & & \\
\hline & & \multirow{2}{*}{ HPE } & -12 & 62.3 & 0.342 & \multirow{2}{*}{-30.9} & \multirow{2}{*}{-24.2} & \multirow{2}{*}{88.2} \\
\hline & & & -18 & 180 & 0.229 & & & \\
\hline & & \multirow{2}{*}{ CWE } & -12 & 80.3 & 0.332 & \multirow{2}{*}{-33.5} & \multirow{2}{*}{-27.8} & \multirow{2}{*}{86.7} \\
\hline & & & -18 & 160 & 0.299 & & & \\
\hline \multirow{18}{*}{$\begin{array}{l}\text { Extended aging } \\
60 \text { hours PAV }\end{array}$} & \multirow{8}{*}{ Binder 1} & & -6 & 143 & 0.299 & & & \\
\hline & & Original & -12 & 263 & 0.258 & -23.3 & -15.8 & 96.6 \\
\hline & & & -18 & 475 & 0.202 & & & \\
\hline & & & -6 & 46.1 & 0.319 & & & \\
\hline & & HPE & -12 & 89.8 & 0.29 & -33.5 & -19.9 & 93.4 \\
\hline & & & -18 & 169 & 0.258 & & & \\
\hline & & & -6 & 55.3 & 0.311 & & & \\
\hline & & CWE & -12 & 112 & 0.289 & -31.3 & -19.0 & 93.0 \\
\hline & & & -18 & 212 & 0.241 & & & \\
\hline & & & -6 & 105 & 0.31 & & & \\
\hline & & Original & -12 & 191 & 0.279 & -26.0 & -17.9 & 101.4 \\
\hline & & & -18 & 374 & 0.223 & & & \\
\hline & & & -6 & 36.5 & 0.372 & & & \\
\hline & Binder 2 & HPE & -12 & 79.8 & 0.309 & -29.4 & -22.6 & 94.6 \\
\hline & & & -18 & 233 & 0.205 & & & \\
\hline & & & -6 & 58.4 & 0.309 & & & \\
\hline & & CWE & -12 & 112 & 0.282 & -32.4 & -18.0 & 96.3 \\
\hline & & & -18 & 198 & 0.265 & & & \\
\hline
\end{tabular}

Both rejuvenated samples performed much better than both control samples, which were made with virgin asphalt. These observations show that RAP binder can even enhance cracking performance of the pavement if it is rejuvenated appropriately. Figure 4 shows the variations of TOT results with APWS aging time.

The results show that the ANCF decreases with increased APWS aging time. This trend confirms that weathering of the pavement makes it more susceptible to fatigue and reflective cracking. The rate of decrease in the ANCF with APWS time was considerably faster for rejuvenated mixtures than for the Control I. This means that cracking susceptibility, which is an indication of aging, increased significantly faster in mixtures containing rejuvenated asphalt than in those made with virgin binder. However, even at the end of 3,000 hours, rejuvenated samples had an equally good or better resistance to cracking when compared with unaged control samples. It can be concluded that although rejuvenated samples have an overall better cracking performance, they might lose their resistance faster than virgin asphalt mixtures. This trend needs further investigation, with more samples and longer aging times.

CWE samples yielded better cracking resistance than HPE samples. The ANCFs of the CWE samples were $10 \%$ to $27 \%$ higher than HPE samples at different aging stages. The CWE is a naphthenic crude emulsion, and HPE is a heavy paraffinic distilled solvent extract. The drop rate in the ANCF with aging time was almost similar for the two rejuvenated mixtures.

It should be noted that there are several factors that limit the generalization of the trends observed. These include the following:

(i) The Texas Overlay Test variability.

(ii) The variability of the air voids between the control and recycled samples.

(iii) The relatively small size of this experiment. 
TABLE 5: Texas overlay test results before and after APWS aging.

\begin{tabular}{|c|c|c|c|c|c|c|}
\hline Mixture & Replicate & Starting load, $\mathrm{kN}$ & Final load, kN & Decline in load, $\%$ & Cycles to failure & Average cycles to failure \\
\hline \multicolumn{7}{|c|}{ O hours } \\
\hline \multirow{3}{*}{ Control I } & 1 & 2.185 & 0.153 & 93 & 55 & \multirow{3}{*}{71} \\
\hline & 2 & 1.724 & 0.117 & 93.2 & 72 & \\
\hline & 3 & 2.325 & 0.159 & 93.2 & 86 & \\
\hline \multirow{3}{*}{ Control II } & $1(\mathrm{SP})$ & 4.230 & 0.282 & 93.3 & 104 & \multirow{3}{*}{63} \\
\hline & $2(\mathrm{SP})$ & 0.155 & 0.008 & 94.7 & 62 & \\
\hline & $3(\mathrm{FC})$ & 2.582 & 0.175 & 93.2 & 24 & \\
\hline \multirow{3}{*}{ HPE } & 1 & 1.653 & 0.112 & 93.2 & 384 & \multirow{3}{*}{239} \\
\hline & 2 & 1.759 & 0.12 & 93.2 & 145 & \\
\hline & 3 & 1.797 & 0.119 & 93.4 & 189 & \\
\hline \multirow{3}{*}{ CWE } & 1 & 1.576 & 1.109 & 93.1 & 347 & \multirow{3}{*}{267} \\
\hline & 2 & 1.742 & 0.118 & 93.2 & 144 & \\
\hline & 3 & 1.707 & 0.118 & 93.1 & 310 & \\
\hline \multicolumn{7}{|c|}{1000 hours } \\
\hline \multirow{2}{*}{ Control I } & 1 & 2.435 & 0.167 & 93.1 & 36 & \multirow{2}{*}{58} \\
\hline & 2 & 2.438 & 0.168 & 93.1 & 79 & \\
\hline \multirow{3}{*}{ HPE } & 1 & 2.213 & 0.151 & 93.2 & 186 & \multirow{3}{*}{186} \\
\hline & 2 & 2.135 & 0.147 & 93.1 & 98 & \\
\hline & 3 & 2.386 & 0.167 & 93 & 275 & \\
\hline \multirow{3}{*}{ CWE } & 1 & 2.53 & 0.174 & 93.1 & 153 & \multirow{3}{*}{253} \\
\hline & 2 & 2.721 & 0.19 & 93 & 256 & \\
\hline & 3 & 2.526 & 0.174 & 93.1 & 349 & \\
\hline \multicolumn{7}{|c|}{3000 hours } \\
\hline \multirow{2}{*}{ HPE } & 1 & 2.987 & 0.23 & 93.2 & 75 & \multirow{2}{*}{71} \\
\hline & 2 & 2.55 & 0.17 & 93.4 & 66 & \\
\hline \multirow{2}{*}{ CWE } & 1 & 2.927 & 0.199 & 93.2 & 58 & \multirow{2}{*}{98} \\
\hline & 2 & 2.663 & 0.18 & 93.3 & 137 & \\
\hline
\end{tabular}

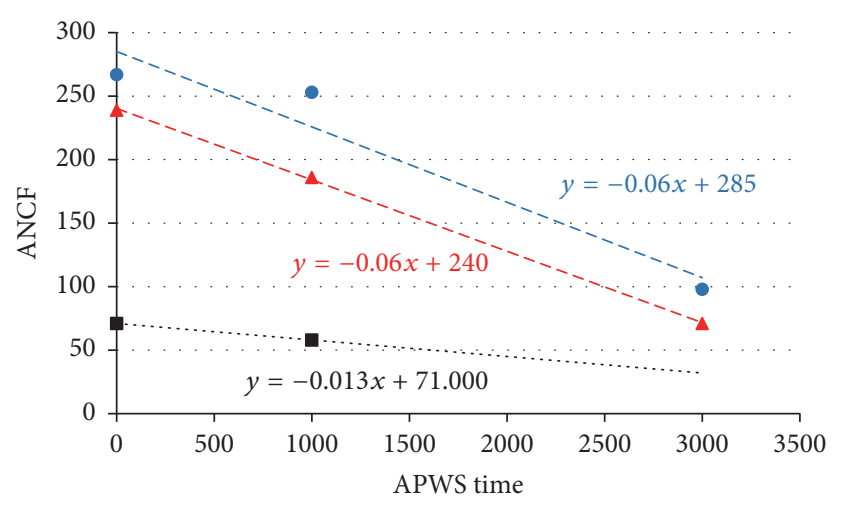

- Control

$\triangle \mathrm{HPE}$

- $\mathrm{CWE}$

FIGURE 4: Variations of the average number of cycles to failure with APWS aging time.

Therefore, the authors will continue this research with further studies, using more samples, and different tests methods, and also using numerical approaches such a finite element method [20] and viscoelastic continuum damage analysis [21].

\section{Conclusions}

The effects of the two rejuvenators on cracking resistance and durability of recycled pavements were investigated using binder and mixture testing. The cracking susceptibility was estimated by the BBR test for binders and TOT for mixtures. PAV and APWS simulated the aging of binder and mixtures, respectively. According to the observations from this study, it was concluded that

(i) generally, rejuvenated binders had significantly better cracking resistance than virgin binders. This fact was observed in both binder and mixture testing. This shows that when performed properly, recycling of the surface layer of a pavement (like in HIR) could potentially provide even more resistance to cracking than placing a new overlay;

(ii) the cracking resistance of rejuvenated mixtures decreased faster than new mixtures. However, even after an accelerated aging procedure that simulated seven to ten years of field aging, rejuvenated mixtures were still more resistant to cracking than unaged new mixtures. It should be noted that the rejuvenators used in this study were deemed as having the best 
durability in a rejuvenated binder aging study previously conducted;

(iii) the cracking resistance of recycled mixtures was affected by the type of rejuvenator. The mixtures rejuvenated with CWE performed better than those rejuvenated with HPE. Further experiments with a wider variety of rejuvenators are needed to investigate this effect, which should be considered when selecting a rejuvenator;

(iv) these conclusions are based on the results from TOT tests. Further work, using different test methods, is needed to verify these observations.

\section{Disclosure}

This study is a part of Dr. Mohammadafzali's Ph.D. dissertation research. Also, the preliminary results of this study were presented in the 2nd world congress and expo on recycling, in 2016, at Berlin, Germany.

\section{Conflicts of Interest}

The authors declare that they have no conflicts of interest.

\section{Acknowledgments}

This research was sponsored by Florida Department of Transportation (FDOT). The authors express appreciation to the department for funding this effort. Special thanks are due to the State Material Office, Bituminous Section, for its support and guidance during this study.

\section{References}

[1] Asphalt Recycling and Reclaiming Association (ARRA), "Basic Asphalt Recycling Manual," Annapolis, Maryland, 2001.

[2] M. Stroup-Gardiner, Recycling and Reclamation of Asphalt Pavements Using In-Place Methods, National Academies Press, Washington, DC, USA, 2011.

[3] H. Haghshenas, H. Nabizadeh, Y. Kim, and K. Santosh, Research on High-RAP Asphalt Mixtures with Rejuvenators and WMA Additives, Department of Roads Research Reports, Lincoln, NE, USA, 2016.

[4] M. Hasaninia and F. Haddadi, "The characteristics of hot mixed asphalt modified by nanosilica," Petroleum Science and Technology, vol. 35, no. 4, pp. 351-359, 2017.

[5] M. Baqersad, A. Hamedi, M. Mohammadafzali, and H. Ali, "Asphalt mixture segregation detection: digital image processing approach," Advances in Materials Science and Engineering, vol. 2017, pp. 1-6, 2017.

[6] J. Zaniewski, S. Knihtila, and H. Rashidi, "Evaluation of the Bond Strength of Asphalt Overlays," in Proceedings of the 2015 ASCE Conference on Afield and Highway Pavements, 2011.

[7] J. Shen, S. Amirkhanian, and B. Tang, "Effects of rejuvenator on performance-based properties of rejuvenated asphalt binder and mixtures," Construction and Building Materials, vol. 21, no. 5, pp. 958-964, 2007.
[8] X. Shu, B. Huang, and D. Vukosavljevic, "Laboratory evaluation of fatigue characteristics of recycled asphalt mixture," Construction and Building Materials, vol. 22, no. 7, pp. 1323-1330, 2008.

[9] N. Sabahfar, A. Ahmed, S. R. Aziz, and M. Hossain, "Cracking resistance evaluation of mixtures with high percentages of reclaimed asphalt pavement," Journal of Materials in Civil Engineering, vol. 29, no. 4, 2017.

[10] M. Zaumanis, R. Mallick, and R. Frank, "Evaluation of rejuvenator's effectiveness with conventional mix testing for $100 \%$ reclaimed Asphalt pavement mixtures," Transportation Research Record, no. 2370, pp. 17-25, 2013.

[11] M. Baqersad, E. A. Sayyafi, and H. M. Bak, "State of the art: mechanical properties of ultra-high performance concrete," Civil Engineering Journal, vol. 3, no. 3, pp. 190-198, 2017.

[12] M. Mohammadafzali, H. Ali, J. A. Musselman, G. A. Sholar, S. Kim, and T. Nash, "Long-term aging of recycled asphalt binders: A laboratory evaluation based on performance grade tests," Airfield and Highway Pavements, Miami, FL, USA, 2015.

[13] Texas DOT, Tex-248-F. Overlay Test, Construction Division, Texas Department of Transportation, 2009.

[14] PRI Asphalt Technology Inc., "What's New, Accelerated Pavement Weathering System (APWS)," June 2015. Available: http:// www.priasphalt.com/news-detail.aspx?id=6.

[15] M. W. Mirza and M. W. Witczak, "Development of a global aging system for short and long term aging of asphalt cements," in Proceedings of the 1995 Conference of the Association of Asphalt Paving Technologists: Asphalt Paving Technology, pp. 393-430, March 1995.

[16] K. Grzybowski, G. M. Rowe, and S. Prince, "Development of an Accelerated Weathering and Reflective Crack Propagation Test Methodology," in Proceedings of the in 7th RILEM International Conference on Cracking in Pavements, 2012.

[17] M. O. Marasteanu, "Role of bending beam rheometer parameters in thermal stress calculations," Transportation Research Record, no. 1875, pp. 9-13, 2004.

[18] C. J. Glover, R. R. Davidson, C. H. Domke et al., "Development of a New Method for Assessing Asphalt Binder Durability with Field Validation," Tech. Rep., 2005.

[19] R. M. Anderson, G. N. King, D. I. Hanson, and P. B. Blankenship, "Evaluation of the relationship between asphalt binder properties and non-load related cracking," Journal of the Association of Asphalt Paving Technologists, vol. 80, 2011.

[20] M. Baqersad, A. E. Haghighat, M. Rowshanzamir, and H. M. Bak, "Comparison of coupled and uncoupled consolidation equations using finite element method in plane-strain condition," Civil Engineering Journal, vol. 2, no. 8, pp. 375-388, 2016.

[21] F. Haddadi, M. Ameri, M. H. Mirabimoghadam, and H. R. A. Hosseini, "Validation of a simplified method in viscoelastic continuum damage (VECD) model developed for flexural mode of loading," Construction and Building Materials, vol. 95, article no. 7000, pp. 892-897, 2015. 


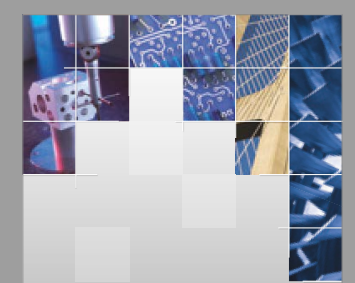

\section{Enfincering}
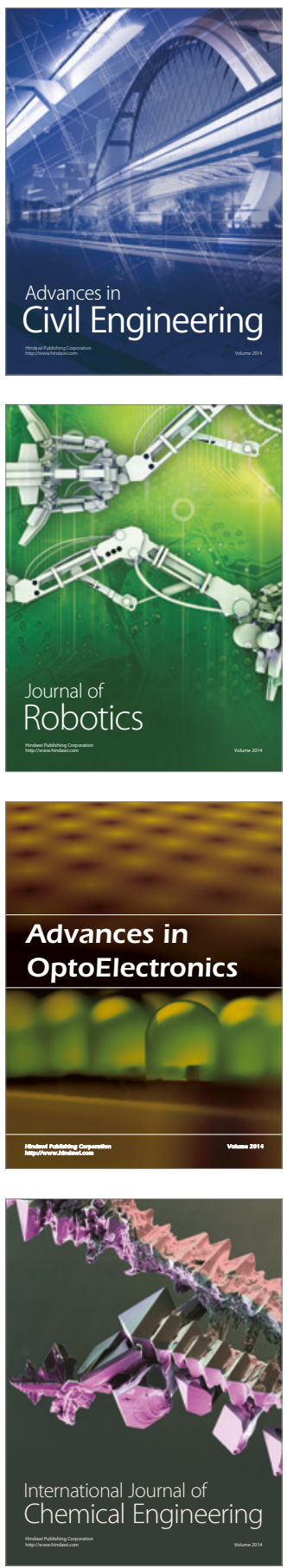

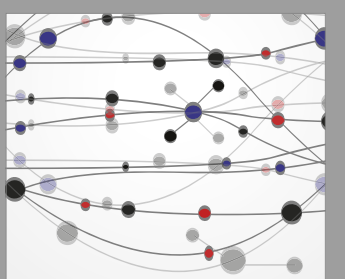

The Scientific World Journal

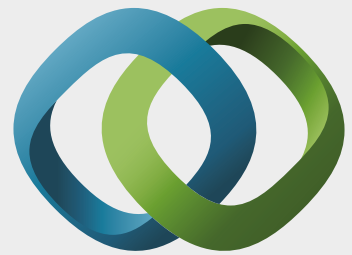

\section{Hindawi}

Submit your manuscripts at

https://www.hindawi.com
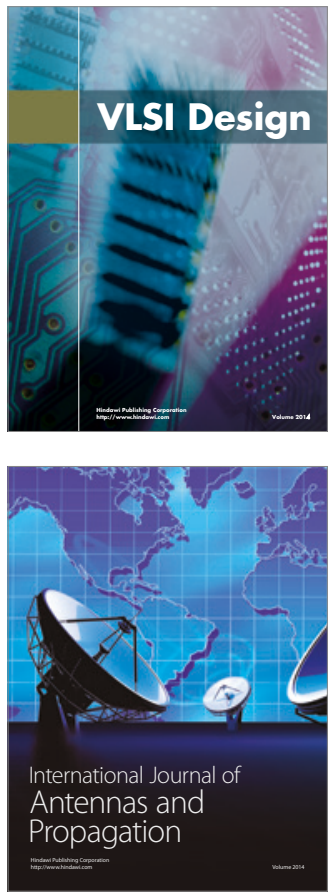

\section{Rotating}

Machinery
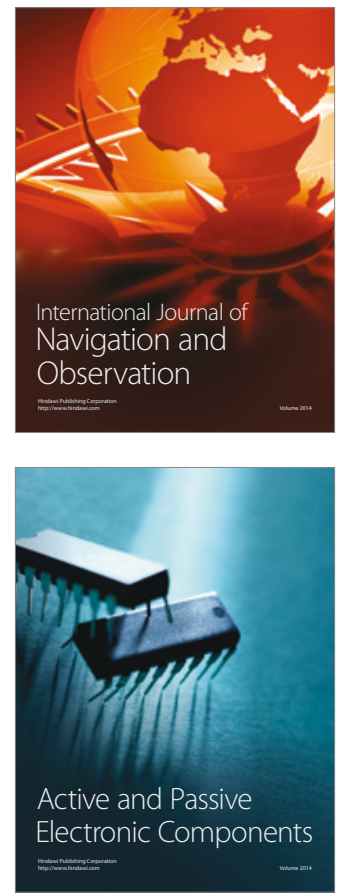
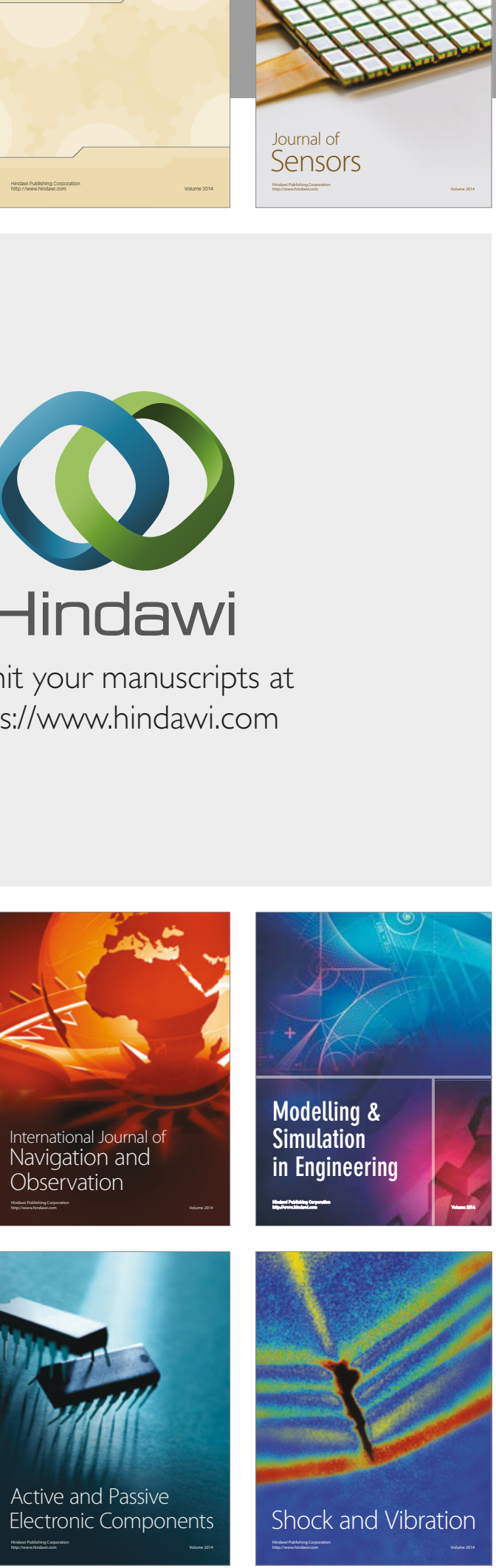
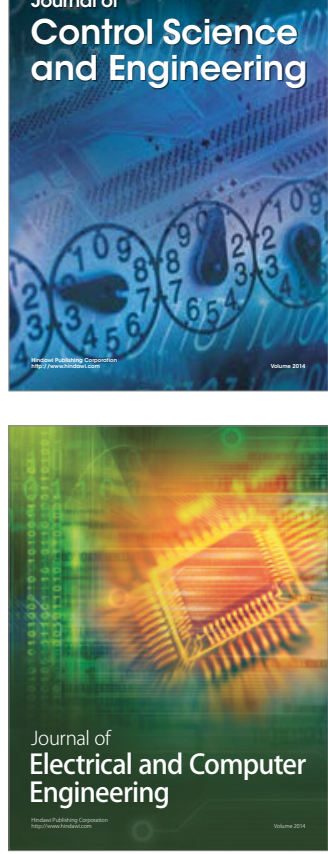

Distributed

Journal of

Control Science

and Engineering
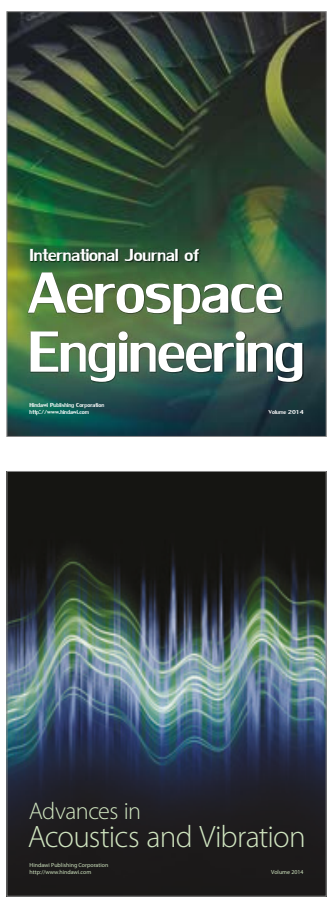

Sensor Networks 